\title{
DESIGNING A 2-DEGREE OF FREEDOM MODEL OF AN UNBALANCED ENGINE AND REDUCING ITS VIBRATIONS BY ACTIVE CONTROL
}

\author{
M. Mohebbi ${ }^{1}$, M. Hashemi ${ }^{*}$ \\ ${ }^{1}$ Faculty of Mechanical Engineering, Department of Applied Mechanics, \\ Universiti Teknologi Malaysia, 81310 Skudai Johor, Malaysia
}

(Received: February 2016 / Revised: September 2017 / Accepted: October 2017)

\begin{abstract}
In this paper, a 2-degree of freedom dynamic model of an unbalanced rotary engine is designed, in a manner that has the effect of modal coupling. After designing the dynamic model in order to reduce the vibrations generated due to the unbalancing mass and modal coupling, the active force control (AFC) method is implemented along with a conventional proportional integral derivative (PID) controller with linear actuators, meaning that the AFC loop is applied as a supplement to the conventional PID controller. The obtained results show that, when the AFC loop was engaged with the PID controller, the vibrations were reduced to nearly zero in both aspects of frequency and amplitude when compared to the case in which only a PID controller was operating in the control system.
\end{abstract}

Keywords: Active Force Control (AFC); PID controller; Unbalanced engine; Vibrations

\section{INTRODUCTION}

The most important features of rotary and reciprocating engines are the crank, connecting rod, and piston. The main cause of vibrations in rotary engines are the inertia forces caused or generated by the moving components (Crede, 1951; Rao, 2016). Analysis of these forces produced due to inertia are explained in detail in normal vibration texts (Rao, 2016).

Vibrations caused by unbalancing usually lead to the damaging of different components in an engine and other parts of the machine, such as the vehicle or turbine (Ogbonnaya et al., 2013; Warminski \& Balthazar, 2003). Therefore, it is important and essential to reduce as much as possible the vibrations that are created by an unbalanced rotary engine and rotary mechanisms, (Kolhar \& Patel, 2013; Ogbonnaya et al., 2013; Warminski \& Balthazar, 2003).

The isolation method is a common and usual method that is implemented for the reduction of unbalanced vibrations of rotary mechanisms and engines, (Soliman \& Hallam, 1968) and in which a flexible platform isolator is taken into consideration for absorbing the vibrations to stop them from damaging other parts and components. An alternative method used for the reduction of the vibrations caused by rotary engines is the active vibration control method (Ruzicka, 1969; Vilnay, 1984). In the active vibration control method, through the implementation of actuators, external forces are applied to the vibrational system, leading to a reduction of the overall vibrations.

To reduce the noise and vibrations produced by rotary engines, the active force control (AFC) method is considered as a closed loop control system. The main advantage of the AFC technique is its ability to discard disturbances or noises that are applied on the system through suitable

\footnotetext{
*Corresponding author's email: m_hashemi8085@yahoo.com, Tel. +60-7-5557065, Fax.+60-7-5557097 Permalink/DOI: https://doi.org/10.14716/ijtech.v8i5.868
} 
selection of the parameters. Furthermore, the AFC technique leads to less computational difficulties and problems, and it also is appropriately established for use in real-time situations. The AFC method was first proposed by Hewit and Burdess (1981), and it was noticed that the AFC method was very robust and operative in controlling a robot arm. Afterward, other researchers implemented the AFC method very successfully for a robot arm by taking into consideration artificial intelligence techniques (Mailah, 1998; Mailah \& Rahim, 2000), in addition to controlling actuators of pneumatic types (Mailah et al., 2009). The AFC method was successful for reducing friction induced vibrations (Hashemi-Dehkordi et al., 2009a; HashemiDehkordi et al., 2009b; Hashemi-Dehkordi et al., 2010; Hashemi-Dehkordi et al., 2012; HashemiDehkordi et al., 2014). The AFC method was implemented for dynamic models of frictioninduced vibrations that were generated by negative damping and modal coupling.

In this paper, the AFC method is applied to a new 2-degree of freedom model of an unbalanced rotary engine, which has the effect of modal coupling in which the AFC loop along with the PID controller was able to reduce the vibrations to a very low amount, in both frequency and amplitude.

At first the design of the 2 degree of freedom model of an unbalanced engine is discussed, and afterwards, the control strategy and methodology is explained.

\section{THE 2-DEGREE OF FREEDOM DYNAMIC MODEL}

In this section, the 2-degree of freedom (DOF) model is designed, and its performance is studied. Until now, almost all dynamic models of an unbalanced rotary engine were represented in 1DOF, as shown in Figure 1 (Crede, 1951; Rao, 2016). The 1-DOF model provides the benefit of easy modeling, controlling, and analyzing.

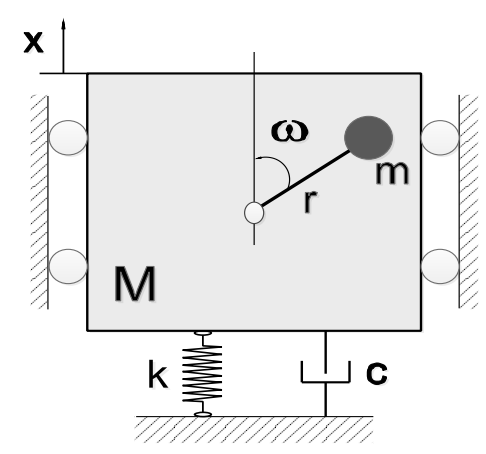

Figure 1 The conventional 1-DOF dynamic model of an unbalanced rotary engine

Yet, in reality or a more complicated manner, it can be seen that in an unbalanced rotary engine or mechanism, vibrations are observed in a plane, meaning that more than one direction of vibration can be seen. This effect could be due to the structure of the supports or fixtures that hold the unbalanced rotary engine; for example, in a vehicle, when the engine is running, vibrations can be felt in all directions of the vehicle chassis and body. Thus, in order to have a more accurate dynamic model of an unbalanced rotary engine, a 2-DOF dynamic model is designed in a manner that also has the effect of modal coupling. Figure 2 shows the 2-DOF model of an unbalanced rotary engine with modal coupling. 


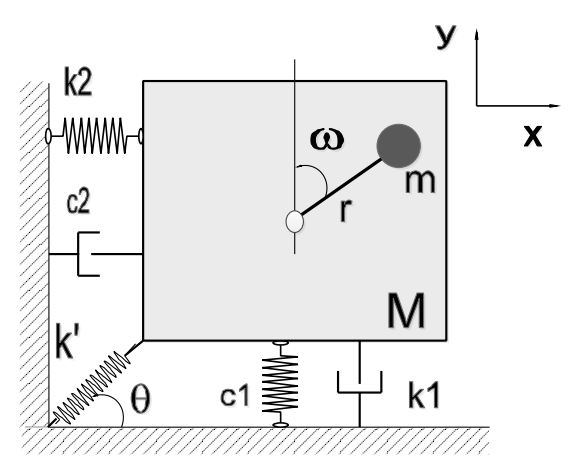

Figure 2 The 2-DOF dynamic model of an unbalanced rotary engine with modal coupling

Figure 2 shows that there are 2 degrees of freedom in plane $(x, y)$ and that there is an unbalanced mass $m$ that rotates at a distant $r$ from the center of the main mass of the engine $M$ with an angular velocity of $w$.

The diagonal spring $k^{\prime}$ is added in order to couple the modes of vibrations and equations. The equation for the motion of the dynamic model is written in Equation 1:

$$
\left\{\begin{array}{c}
M \ddot{x}+c_{2} \dot{x}+k_{2} x+k^{\prime}(d \cdot \cos \theta)-m r \omega^{2} \sin (\omega \cdot t)=0 \\
M \ddot{y}+c_{1} \dot{y}+k_{1} y+k^{\prime}(d \cdot \sin \theta)-m r \omega^{2} \cos (\omega \cdot t)=0 \\
d=\sqrt{x^{2}+y^{2}}=x \cdot \cos \theta+y \cdot \sin \theta
\end{array}\right.
$$

where $M$ is the mass of the rotary engine, $m$ is the mass of the unbalanced rotation, $r$ is the radius of the unbalanced mass form the axis of rotation, $w$ is the angular velocity, and $t$ is time.

By using Matlab Simulink, the equation of motion was simulated, and the behavior of the 2-DOF model was studied. It should be mentioned that nearly zero damping was considered for this simulation. The values of the variables that were considered and assigned for this simulation are as follows:

$$
\begin{aligned}
& M=20 \mathrm{~kg} \\
& m=0.6 \mathrm{~kg} \\
& r=0.15 \mathrm{~m} \\
& \mathrm{w}=5000 \mathrm{rpm} \\
& \Theta=60^{\circ} \\
& k=1.8 \times 10^{7} \mathrm{~N} / \mathrm{m} \\
& k_{1}=1 \times k \\
& k_{2}=0.75 \times k \\
& k^{\prime}=0.35 \times k \\
& c_{1} \text { and } c_{2}=0.0005 \mathrm{~N} . \mathrm{s} / \mathrm{m}
\end{aligned}
$$

The block diagram of the 2-DOF model (also called the passive system) by Matlab Simulink is represented in Figure 3. After executing the simulation by Matlab Simulink in a 120-seconds time span, the results were obtained in both time and frequency domains. Figure 4 represents the obtained results.

As seen from the results in Figure 4, for direction $x$, the amount of amplitude is around $4.8 \mathrm{~mm}$, and for direction $y$, the amplitude is around $3.1 \mathrm{~mm}$. There are also 3 frequency pikes for each direction with almost the same hertz. 


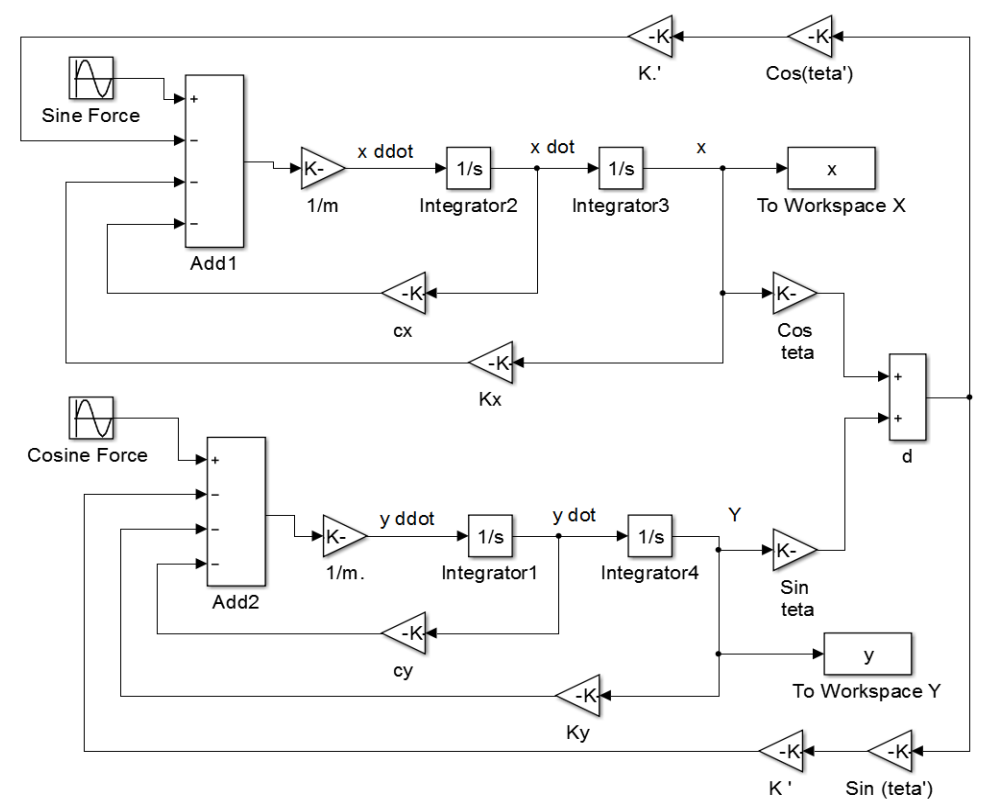

Figure 3 The block diagram of the 2-DOF dynamic model (passive system)

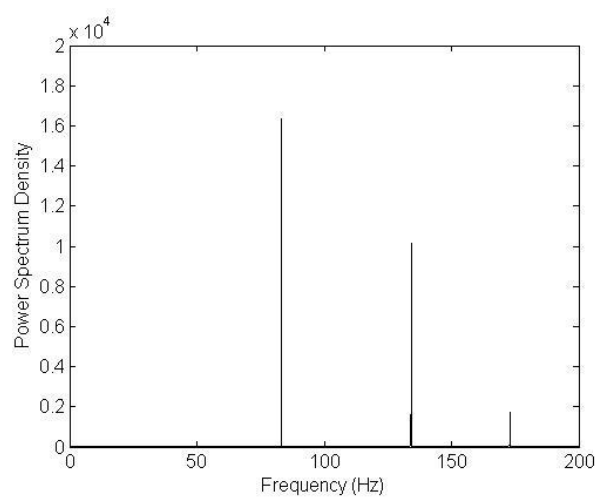

(a) ' $x$ ' Frequency

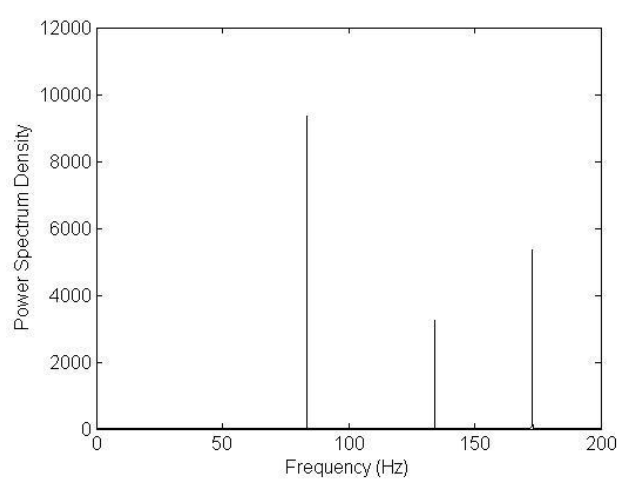

(c) ' $y$ ' Frequency

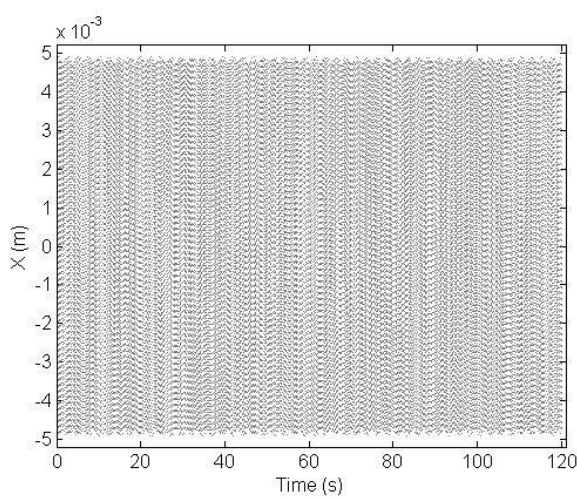

(b) $x(m)$

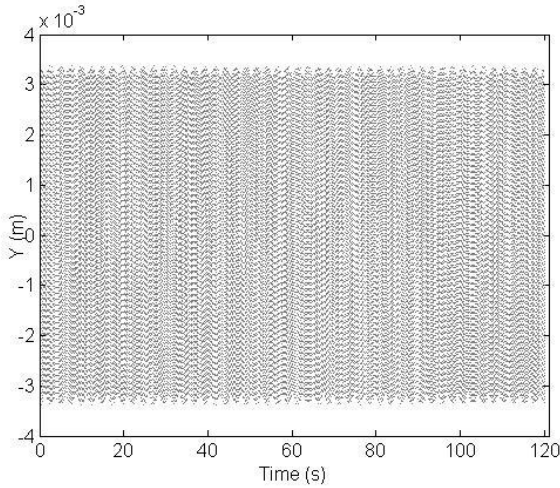

(d) $y(m)$

Figure 4 The obtained results of the 2-DOF model in time domain and frequency domain (passive system)

\section{CONTROL STRATEGY AND ITS SIMULATION}

To reduce the noise and vibrations of the 2-DOF dynamic model of an unbalanced engine, the AFC method is taken into consideration. Figure 5 shows the schematic diagram of the AFC loop. 


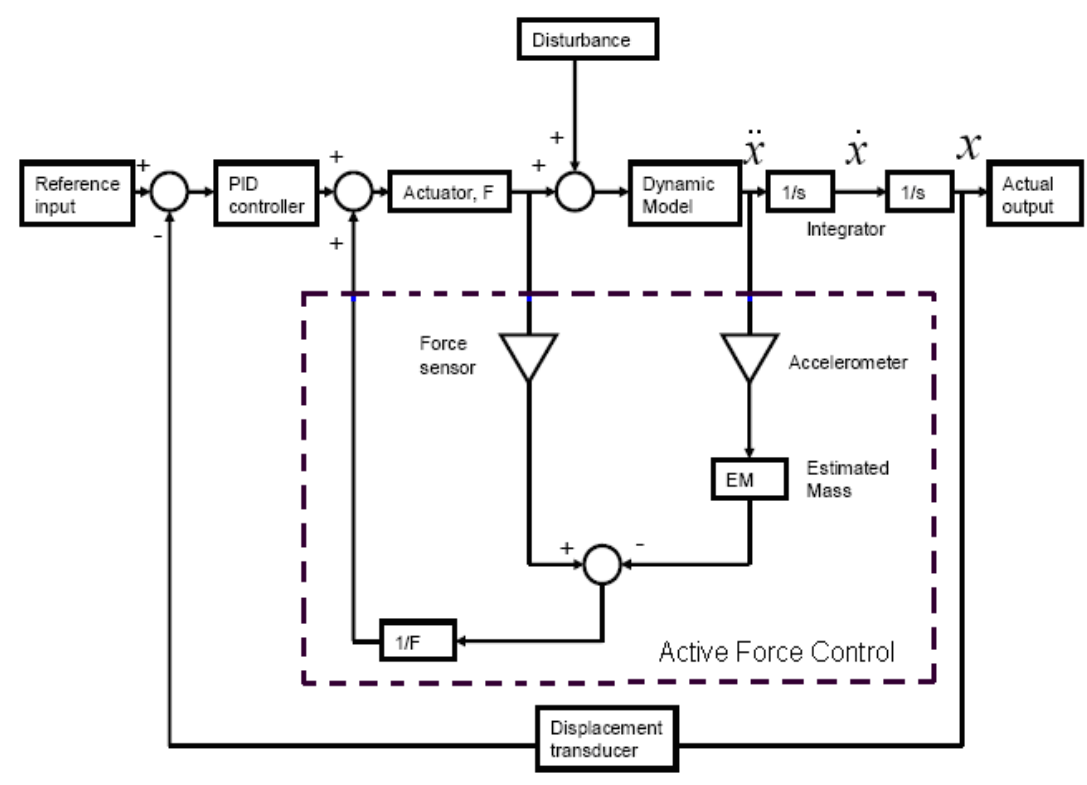

Figure 5 The block diagram of active force control

The main $\mathrm{AFC}$ equation is obtained by calculating the disturbance $\mathrm{F}_{d}$ as in Equation 2:

$$
F_{d}=F-m_{E M} a
$$

where $F$ is the force that is applied by the actuator, $a$ represents acceleration, and $m_{E M}$ is the estimated mass. The value $\mathrm{F} d$ is later multiplied through the inverse transfer function of the actuator and, at the end, is summed up with the signal of the PID control. More detail of the analysis of the AFC methodology is explained by Burdess and Hewit (1986).

To simulate the control strategy, Matlab Simulink was implemented, and in order to tune the PID controller, the Ziegler--Nichols method was taken into consideration afterwards for better performance the values which were obtained for the PID controller were manipulated by crude approximation. The values of the estimated masses were obtained by the trial-and-error method. The Simulink block diagram of the control strategy is shown in Figure 6 (the active system). The obtained values for the estimated masses for each direction of the degree of freedom are written below and they were obtained from Mohebbi and Hashemi (2016), and trial and error:

For the horizontal direction $x$ :

Estimated mass $\left(m_{E M}\right): 6.3$

Actuator coefficient: 6.0

Proportional value for the PID controller: 2.50

Integrational value for the PID controller:

4.10

Derivative value for the PID controller: 6.40
For the horizontal direction $y$ :

Estimated mass (mEM): 5.8

Actuator Coefficientcoefficient: 5.7

Proportional value for the PID controller: 2.20

Integrational value for the PID controller: 3.65

Derivative value for the PID controller: 6.25 


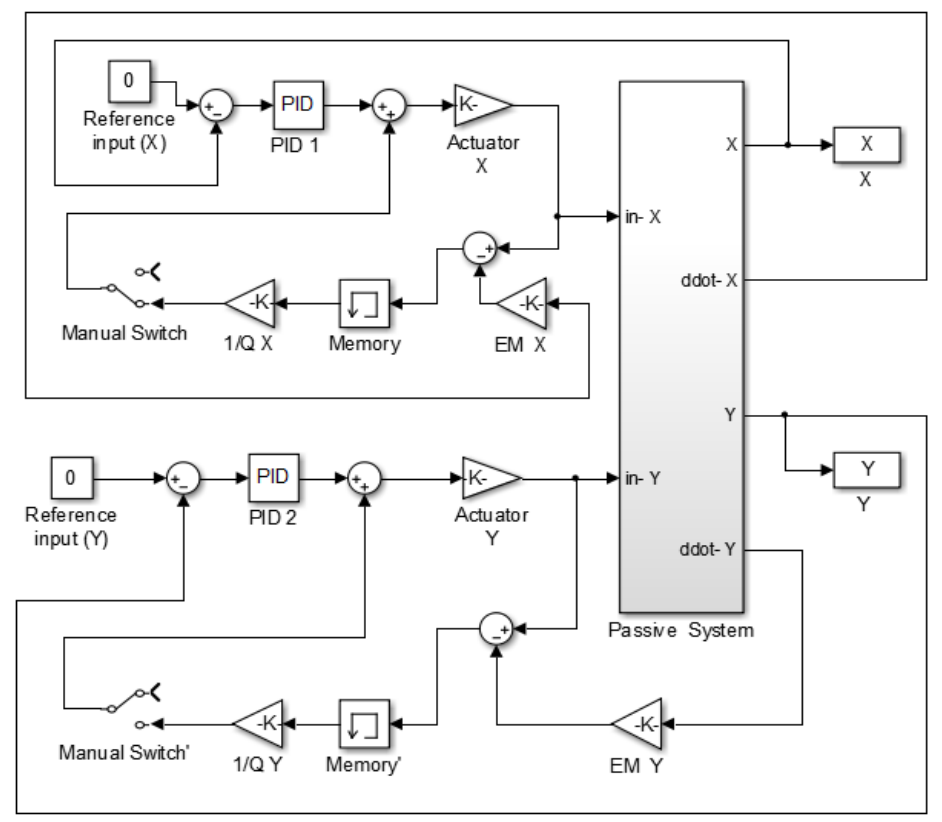

Figure 6 The Simulink block diagram of the control strategy (active system)

\section{RESULTS AND DISCUSSION}

At first, the control system was considered to be operating with only having PID controllers, meaning that the AFC loop was not engaged. Afterwards the simulation was executed again but with the difference that the control system was operating with both PID controllers and the AFC loops engaged.

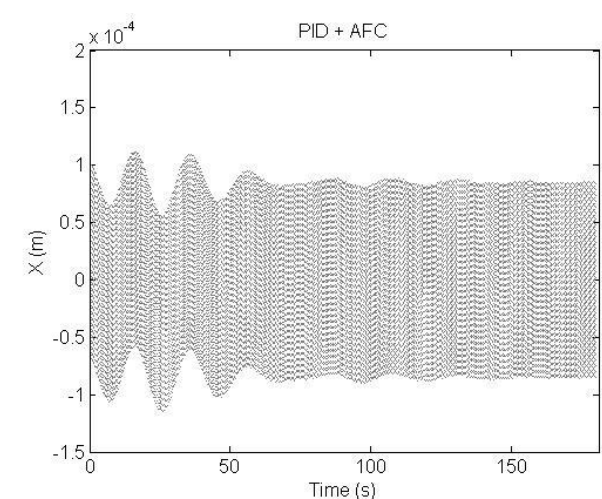

(a) PID + AFC

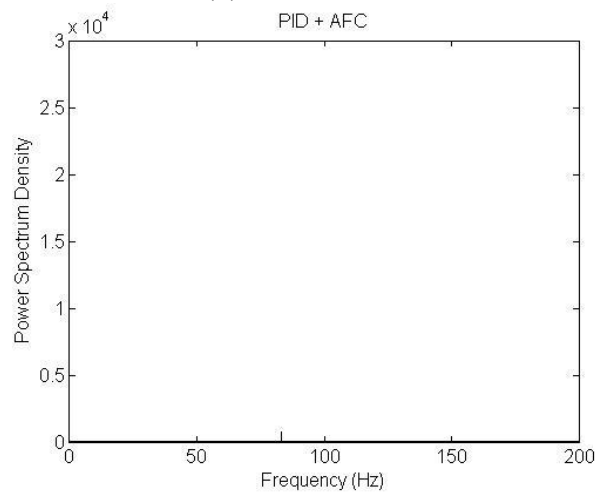

(c) PID + AFC (frequency domain)

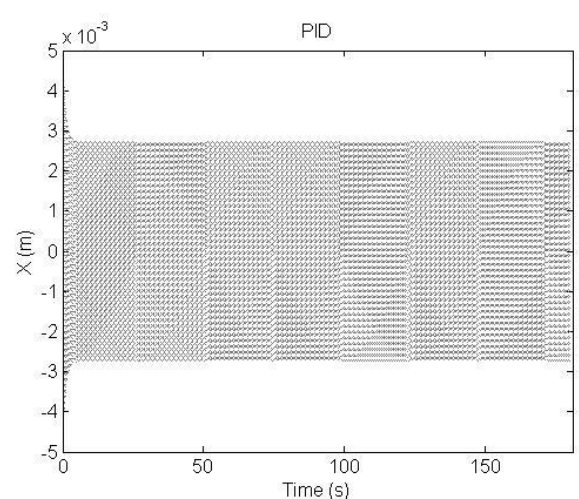

(b) PID

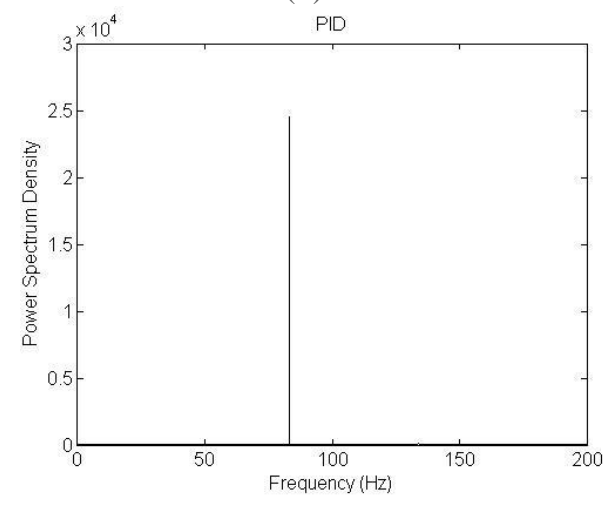

(d) PID (frequency domain)

Figure 7 Results of the control system for the horizontal $(x)$ direction 
Figure 7 and Table 1 show the obtained results of the simulation for the horizontal $x$ direction $x$, in both the time and frequency domains. It can be seen that, when the control system is operating with only PID controllers, the amplitude of the vibrations reduces (to $2.8 \mathrm{~mm}$ ) in comparison to the case in which the dynamic model was operating without any controllers (passive system), and the frequency domain results show that the pikes have reduced from 3 to 1 . On the contrary, when the control system is operating with the AFC loop involved, from the obtained results, it can be seen that the amount of amplitude reduces to less the $0.1 \mathrm{~mm}$ and the amplitude of the frequency reduces to nearly zero.

Figure 8 and Table 1 show the results obtained from the simulation in the vertical direction $y$, and again it can be seen that, for both the time and frequency domains, when the control system is operating with only PID controllers, the vibrations reduce to less than $1.5 \mathrm{~mm}$, but when the AFC loop is engaged with the PID controllers, the amplitude reduces to less than $0.2 \mathrm{~mm}$. The same situation is observed for the frequency domain results.

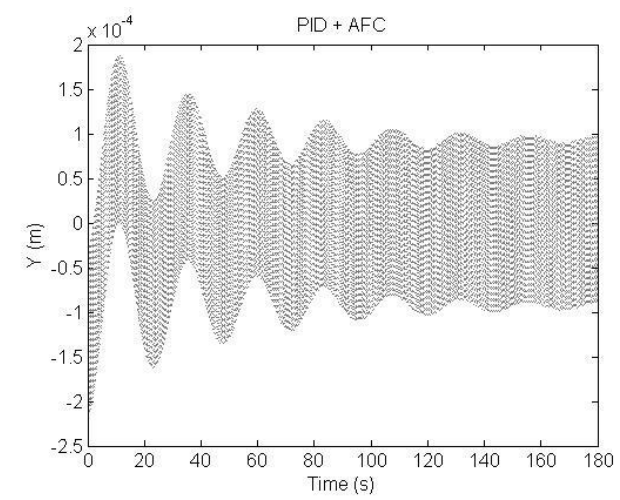

(a) $\mathrm{PID}+\mathrm{AFC}$

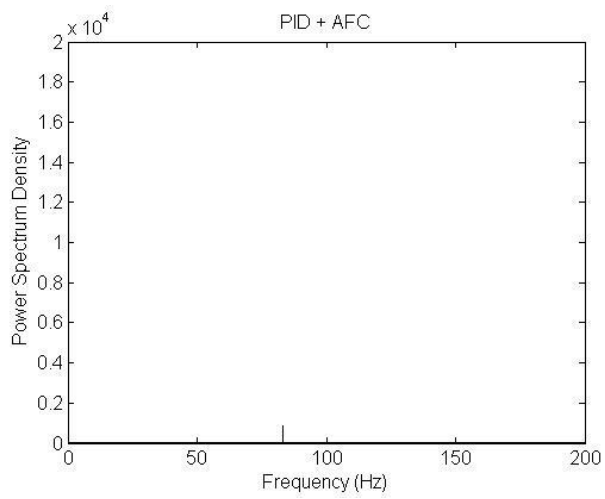

(c) PID + AFC (frequency domain)

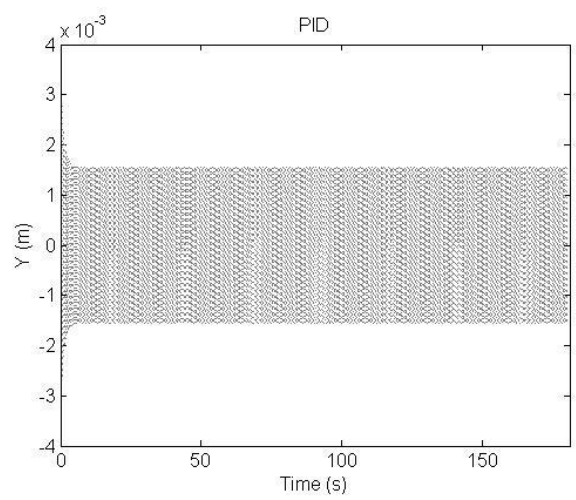

(b) PID

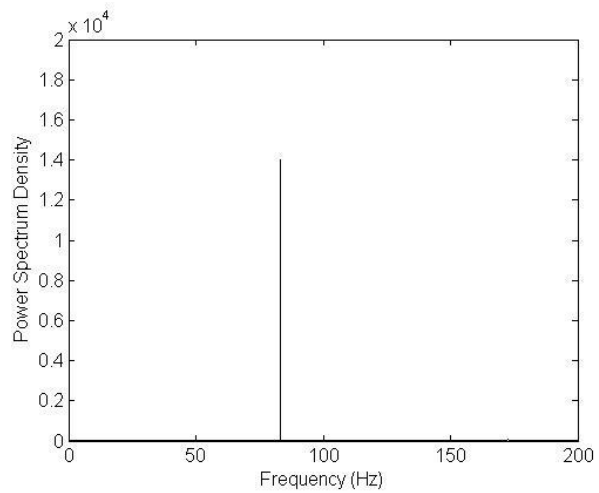

(d) PID (frequency domain)

Figure 8 Results of the control system for the vertical $(y)$ direction

Table 1 Obtained results

\begin{tabular}{ccccc}
\hline Direction & $\mathrm{x}$ (Normal load) & $\mathrm{y}$ (Normal load) & $\mathrm{x}$ (Overload) & $\mathrm{y}$ (Overload) \\
\hline PID & $2.8 \mathrm{~mm}$ & $1.5 \mathrm{~mm}$ & $4.5 \mathrm{~mm}$ & $3.0 \mathrm{~mm}$ \\
PID + AFC & $\mathrm{x}<0.1 \mathrm{~mm}$ & $\mathrm{y}<0.2 \mathrm{~mm}$ & $\mathrm{x}<0.3 \mathrm{~mm}$ & $\mathrm{y}<0.4 \mathrm{~mm}$ \\
\hline
\end{tabular}

In order to examine the robustness of the control system when the external forces were increased, another simulation was executed, in which both the unbalanced mass and the rotational velocity 
were increased from $0.6 \mathrm{~kg}$ to $1 \mathrm{~kg}$ and from $5000 \mathrm{rpm}$ to $6000 \mathrm{rpm}$. The time domain results of this simulation are shown in Figure 9 and Table 1 for both directions $x$ and $y$, and it can be seen that, when the control system is operating with both PID and AFC, the vibrations are still less than $0.5 \mathrm{~mm}$ in amplitude.

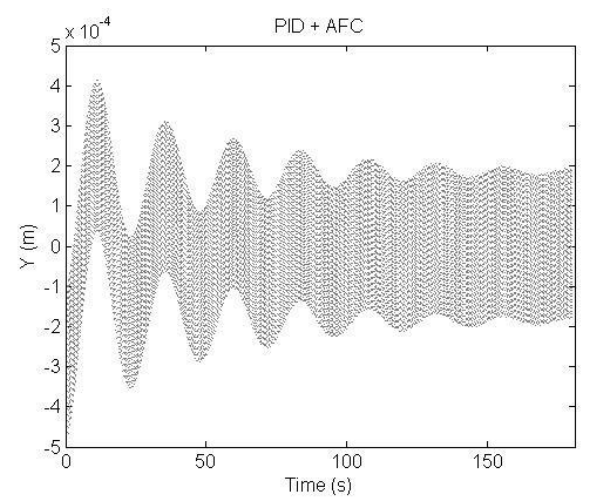

(a) $\mathrm{PID}+\mathrm{AFC}(y)$

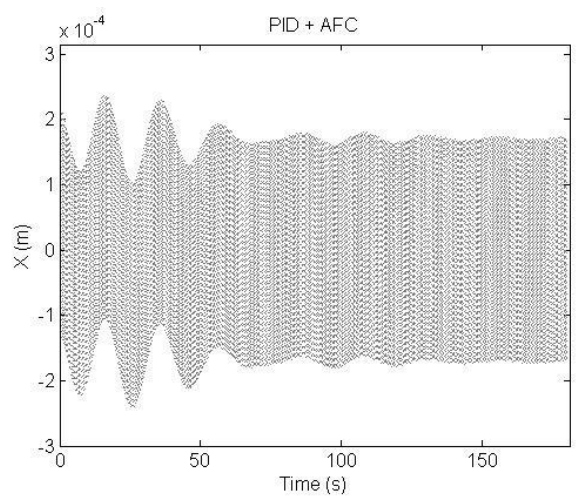

(b) $\mathrm{PID}+\mathrm{AFC}(x)$

Figure 9 The results of the control system when both unbalanced mass and rotational velocity are increased to $1 \mathrm{~kg}$ and $600 \mathrm{rpm}$, respectively

\section{CONCLUSION}

A novel 2-DOF dynamic model of an unbalanced rotary engine was designed, in which it also has the effect of modal coupling. The behavior of this model was simulated, observed, and studied. In order to reduce the vibrations and noise in the designed dynamic model, the AFC method was implemented. After designing and tuning the PID and AFC parameters, the simulation results were obtained. From the obtained results, it was noticed that, when the control system is operating with only PID controllers, the vibrations were reduced but not with a high level of amplitude. On the contrary, while the control system was operating with both PID and AFC, the amplitude of the vibrations was reduced to a very noticeable amount. This situation was also was observed in frequency domain results as well. Also, in order to examine the robustness of the control system, both unbalanced mass and rotational velocity were increased, and the obtained results proved that, when the control system is equipped with the AFC loop, the vibrations still are reduced to less than $0.5 \mathrm{~mm}$.

\section{REFERENCES}

Burdess, J.S., Hewit, J.R., 1986. An Active Method for the Control of Mechanical Systems in the Presence of Unmeasurable Forcing. Mechanism and Machine Theory, Volume 21(5), pp. 393-400

Crede, C.E., 1951. Vibration and Shock Isolation, Wiley, New York

Hashemi-Dehkordi, S.M., Abu Bakar, A.R., Mailah, M., 2012. Reducing Friction-induced Vibration using Intelligent Active Force Control (AFC) with Piezoelectric Actuators. SADHANA Academy Proceedings in Engineering Sciences, Volume 37, Part 6, pp. 637-655

Hashemi-Dehkordi, S.M., Abu Bakar, A.R., Mailah, M., 2014. Stability Analysis of a Linear Friction-induced Vibration Model and Its Prevention using Active Force Control. Advances in Mechanical Engineering, Volume 2014, pp. 1-13

Hashemi-Dehkordi, S.M., Mailah, M., Abu Bakar, A.R., 2009a. Implementation of Active Force Control to Disk Brake Noise-Free Performance. International Review of Mechanical Engineering (IREME), Volume 3(4), pp. 481-488

Hashemi-Dehkordi, S.M., Mailah, M., Abu Bakar, A.R., 2009b. Intelligent Active Force Control 
with Piezoelectric Actuators to Reduce Friction Induced Vibration due to Negative Damping. International Review of Electrical Engineering (IREE), Volume 4(6), pp. 1294-1305

Hashemi-Dehkordi, S.M., Mailah, M., Abu Bakar, A.R., 2010. Suppressing Friction-induced Vibration due to Negative Damping and Mode Coupling Effects using Active Force Control. Australian Journal of Basic and Applied Sciences, Volume 4(8), pp. 3917-3933

Hewit, J.R., Burdess, J.S., 1981. Fast Dynamic Decoupled Control for Robotics using Active Force Control. Transactions on Mechanism and Machine Theory, Volume 16(5), pp. 535542

Kolhar, S.S., Patel, D.R., 2013. Optimization of a Drum Type Washing Machine by Analytical and Computational Assessment. International Journal of Scientific \& Engineering Research, Volume 4(6), pp. 2759-2764

Mailah, M., 1998. Intelligent Active Force Control of a Rigid Robot Arm using Neural Network and Iterative Learning Algorithms. Unpublished PhD thesis, University of Dundee, United Kingdom

Mailah, M., Jahanabadi, H., Zain, M.Z.M., Priyandoko, G., 2009. Modelling and Control of Human-like Arm using Active Force Control. In: Proceedings of the Institute of Mechanical Engineering Part C: Journal of Mechanical Engineering Science, Volume 223

Mailah, M., Rahim, N.I.A., 2000. Intelligent Active Force Control of a Robot Arm using Fuzzy Logic. In: Proceedings of IEEE International Conference on Intelligent Systems and Technologies, Kuala Lumpur, Malaysia, Volume 2, pp. 291-296

Mohebbi, M., Hashemi, M., 2016. Reducing the Vibrations of an Unbalanced Rotary Engine by Active Force Control. International Journal of Technology, Volume 7(1), pp. 141-148

Ogbonnaya, E.A., Ugwu, H.U., Poku, R., Adigio, E.M., 2013. Active Condition Monitoring of a Marine Gas Turbine through Rotor Shaft Vibration Analysis. American Journal of Mechanical Engineering, Volume 1(4), pp. 82-88

Rao, S.S., 2016. Mechanical Vibrations, $6^{\text {th }}$ ed., Prentice Hall, New York

Ruzicka, J.E., 1969. Active Vibration and Shock Isolation. Society of Automotive Engineering Transactions, Volume 77, pp. 2872-2886

Soliman, J.I., Hallam, M.G., 1968. Vibration Isolation between Non-rigid Machines and Nonrigid Foundations. Journal of Sound and Vibration, Volume 8, pp. 329-351

Vilnay, O., 1984. Active Control of Machinery Foundation. Journal of Engineering Mechanics, American Society of Civil Engineering, Volume 110, pp. 273-281

Warminski, J., Balthazar, J.M., 2003. Vibrations of a Parametrically and Self-excited System with Ideal and Non-ideal Energy Sources. Journal of the Brazilian Society of Mechanical Sciences and Engineering, Volume 25(4), pp. 413-420 